\title{
EL DISCURSO SUBVERSIVO DE PATRICIA ESTEBAN ERLÉS EN EL CONTEXTO DE LO FANTÁSTICO FEMINISTA ${ }^{1}$
}

\author{
THE SUBVERSIVE DISCOURSE OF PATRICIA ESTEBAN ERLÉS \\ IN THE CONTEXT OF THE FEMINIST FANTASTIC
}

\author{
Natalia ÁLVAREZ MÉNDEZ \\ Universidad de León \\ natalia.alvarez@unileon.es
}

\begin{abstract}
Resumen: La poética fantástica de Patricia Esteban Erlés (Zaragoza, 1972) constituye una contestación al ideario conservador asumido por nuestro imaginario cultural. Así lo demuestran características relativas a la selección y el tratamiento de los personajes, la temática, la construcción y la significación del espacio narrativo, el modo de abordar la monstruosidad derivada de la realidad sexista, las propuestas formales y la apuesta por el hibridismo genérico. Su análisis estará imbricado con reflexiones sobre la consolidación de esta línea de lo fantástico feminista en las últimas décadas en el ámbito de la narrativa en español y sobre la posible existencia de un canon de autoras, tanto en español como en otras lenguas, que haya podido influir en esa fragua de lo fantástico escrito por mujeres con una clara perspectiva política, en la que lo no mimético se convierte en una herramienta ideológica de denuncia social y genérica.
\end{abstract}

Palabras clave: Esteban Erlés. Insólito. Fantástico. Feminista. Subversión.

\begin{abstract}
Born Zaragoza, 1972, Patricia Esteban Erlés's poetics of fantastic represents a contestation to the conservative ideology assumed by our cultural imaginary. This is demonstrated by some characteristics related to the selection and treatment of characters, the subject, the construction and the signification of the narrative space, the approach to monstrosity as derived from sexist reality, the formal proposals and the inclination towards generic hybridism. Its analysis will be interweaved with reflections on the consolidation of this trend of the feminist fantastic in the last decades in the Spanish narrative panorama and the possible existence of a female writers canon, both in Spanish and other languages, that could have influenced the forging of the fantastic written by women with a clear political perspective in which non-mimetic genres have become an ideological tool for gender and social denunciation.
\end{abstract}

Keywords: Esteban Erlés. Fantasy. Fantastic. Feminist. Subversion.

\footnotetext{
${ }^{1}$ El artículo es resultado del proyecto de investigación Estrategias y figuraciones de lo insólito. Manifestaciones del monstruo en la narrativa en lengua española (de 1980 a la actualidad, del Ministerio de Ciencia, Innovación y Universidades (PGC2018-093648-B-I00, I.P. Dra. Natalia Álvarez Méndez).
} 


\section{LA FRAGUA DE ESPECIFICIDADES EN LA POÉTICA DE LO FANTÁSTICO DESDE LA AUTORÍA FEMENINA}

En un país como España, con una amplia tradición de defensa de la literatura realista, se está reivindicando cada vez con más fuerza desde medios académicos el lugar alcanzado por la estética fantástica. Se ha constatado su normalización en las décadas de los ochenta y los noventa del siglo XX (Roas y Casas, 2008, 2010), y también su creciente cultivo y vitalidad en la cultura española en el siglo XXI (Álvarez Méndez, 2013; Abello Verano, 2016), con el desarrollo de una poética específica (Roas, 2011; Roas, Álvarez y García, 2017). Sin embargo, no cabe duda de que todavía habrá que desarrollar una labor futura de defensa de esta categoría y de que, por supuesto, en ese quehacer será de obligado cumplimiento reivindicar la impronta de la autoría femenina, que destaca por un número creciente de creadoras, pero todavía con escasa presencia en el canon ${ }^{2}$. Desatender ese corpus nos llevaría a ofrecer una visión incompleta tanto de la evolución de lo fantástico y sus fronteras genéricas en el marco de la literatura no mimética como de la producción literaria desarrollada por las mujeres en general. Es preciso, pues, reflexionar sobre las singularidades de la escritura de las narradoras, tanto temáticas como estructurales, asociadas en muchos casos a una visión feminista. No en vano, la lectura crítica de la realidad de género en nuestras sociedades es una materia importante que no se puede soslayar porque afecta a un número importante de ficciones en las que se potencia el cuestionamiento del orden simbólico institucionalizado y normativo que ya de por sí persigue la literatura fantástica.

En la actualidad, asistimos a un tiempo en el que, a pesar de que la mujer todavía se enmarca en una persistente situación de desigualdad en muchos ámbitos, existen afanes enfocados a fomentar su visibilización. Así sucede en la esfera de la escritura, en la que, durante muchos siglos, como todos sabemos, la firma femenina quedaba excluida del canon literario. Estos esfuerzos de reivindicación parece que necesitan incrementarse cuando nos enfrentamos a las figuraciones de lo insólito, ya que la propia literatura no mimética ha sufrido durante mucho tiempo la marginación, ha sido considerada como una vertiente creativa inferior frente al centro canónico constituido por la literatura realista. A pesar de ello, contamos en pleno siglo XXI con un nutrido número de escritoras que han logrado situar la literatura de lo insólito en un relevante lugar de nuestro panorama editorial actual. De tal modo, en la narrativa no mimética hispánica de las últimas décadas destacan la fuerza y la singularidad de obras de creadoras que ofrecen, en cierto grado, una renovación de los discursos tradicionales. En sus publicaciones se descubren ejes

\footnotetext{
2 "The fantastic is particularly prolific in Hispanic countries during the twentieth and twenty-first centuries, largely due to the legacy of writers such as Jorge Luis Borges and Julio Cortázar, as well as the LatinAmerican boom, which presented alternatives to the predominant model of literary realism. While their works have done much to establish the Hispanic fantastic in the international literary canon, women authors from Spain and Latin America are much less acknowledged and in general less well known to readers" (García, 2019: 569).
} 
temáticos desarrollados a través de matices prácticamente ausentes en las narraciones de firma masculina, así como peculiaridades en el tratamiento de los personajes, de las voces narradoras y de lo siniestro y lo monstruoso. A ello se suma una preferencia de las creadoras por los discursos breves, el fragmentarismo y el hibridismo genérico.

Se puede argumentar, por lo tanto, que en el ámbito de la narrativa en español se está fortaleciendo una línea no solo de autoría de mujer, sino de lo que podríamos denominar fantástico feminista. Podríamos hablar, incluso, de lo insólito feminista, pues, como acabo de mencionar, el hibridismo genérico de las categorías de lo no mimético es un rasgo caracterizador de las obras de estas autoras. Recordemos que, tomando como punto de partida de reflexión el término fantastique féminin acuñado por Anne Richter (1977) - con el que defiende la especificidad de la imaginación femenina en el cultivo de lo fantástico y la relaciona con el mundo interior, lo irracional y la locura-, parte de la crítica ha defendido una visión esencialista y arquetípica de lo femenino ${ }^{3}$. Conviene refutar esas dicotomías patriarcales que oponen al hombre y a la mujer, y que perpetúan la definición errónea de una identidad colectiva de esta última. Debemos tener en cuenta las individualidades que caracterizan a la mujer, hecho sobre el que existen destacadas reflexiones como las de Foucault en su Hermenéutica del sujeto (1994) o las de Judit Butler en El género en disputa (2001), por poner solo dos ejemplos paradigmáticos que demuestran que es necesario reformular ese limitado concepto de identidad femenina transferida a lo largo del tiempo. En caso contrario, estaríamos incurriendo en el modelo literario patriarcal que transmitió durante muchos siglos la imagen de la mujer entendida como alteridad del sujeto masculino y que implantó un modelo binario que a día de hoy no se puede sostener, pues asocia al hombre a la razón, la objetividad y lo público, presentando a la mujer como excluida del ámbito intelectual y sociopolítico, relegada a lo privado, y vinculada a la naturaleza, a las emociones, los afectos, la subjetividad y el cuerpo $^{4}$. Pero el rechazo del esencialismo, es decir, de lo fantástico femenino tal como lo definen Ritcher y sus seguidores, no está reñido con que se pueda reivindicar el término de lo fantástico feminista. Es complicado sostener que existe un fantástico que remite a esenciales femeninos latentes en todas las creadoras, pero sí se puede argumentar la existencia de un fantástico feminista que trata de deconstruir la configuración cultural propia del modelo patriarcal. Así lo ha defendido recientemente David Roas (2020: 2327), tras profundizar en esta problemática y revisar teorizaciones que apoyan un posible uso feminista de lo fantástico ${ }^{5}$, entre ellas las de Anne Cranny-Francis (1990) y Gloria Alpini (2009):

\footnotetext{
${ }^{3}$ Para ampliar información sobre dicho posicionamiento crítico, véase la revisión realizada por David Roas (2020: 15-18) de algunas de esas destacadas visiones esencialistas que se hacen eco o perpetúan el concepto de fantástico femenino de Ritcher varias décadas después.

${ }^{4}$ En ello ha insistido la teoría crítica feminista francesa. Recordemos las ideas al respecto de Hélène Cixous (1995), entre otras.

${ }^{5}$ Uso en el que ahonda Anna Boccuti (2020) al relacionar la subversión fantástica con la ironía feminista en las narradoras fantásticas e insólitas de habla hispana, entre ellas Patricia Esteban Erlés.
} 
Un empleo, pues, feminista de lo fantástico cada vez más extendido en autoras de diversos países y lenguas, y en diversas artes, lo que implica la presencia recurrente de estas características antes mencionadas: voces femeninas para exponer en primera persona la experiencia de lo fantástico; personajes femeninos cuyas historias traducen un constante movimiento de reconstrucción identitaria frente a la identidad estereotipada construida por la heterodesignación del discurso hegemónico patriarcal, lo que, a la vez, implica la inversión de los roles femeninos (y la consiguiente deconstrucción de esos estereotipos) y la destacada presencia de la monstruosidad femenina (Creed, 1993) como forma de denuncia y transgresión de los modelos tradicionales, tanto en lo referente a la representación del cuerpo como a los límites de la monstruosidad y, sobre todo, a la violencia y el horror como reflejo de la opresión sobre la mujer (Roas, 2020: 27).

En las ficciones de las creadoras hispánicas de lo insólito, lo no mimético pone de relieve el testimonio de concretas problemáticas sociales propias de nuestra realidad y realiza una aproximación a lo terrible que se esconde bajo la posibilidad de existencia de esos horrores en nuestro mundo. Por lo tanto, no se trata de postular una subjetividad femenina distintiva en cuanto a esencialista, sino de constatar que narraciones de algunas de estas autoras, enfocadas desde una perspectiva política feminista, más o menos explícita, demuestran que la mujer confluye en una mirada singular que, aunque plena de matices individuales, está marcada por su experiencia y trasvasada a la creación artística a través de una ficción - envuelta en lo inquietante, lo extraño y lo fantástico - con la que se profundiza en las fracturas de nuestra realidad desde la ambigüedad propiciada por las modalidades no miméticas. En estos casos, las estéticas de lo insólito se convierten en una herramienta de testimonio y de denuncia de la marginación y de las formas de dominación a las que ha sido sometida la mujer, reseñadas, por ejemplo, en la Microfísica del poder (Foucault, 1979), y entre las que sobresalen no solo las de alianza sino también las de sesgo sexual y familiar.

Lo cierto es que, en el actual siglo XXI, el ensamblaje de lo realista con lo fantástico, lo maravilloso, el terror y la ciencia ficción ofrece una retórica particular caracterizada por las dinámicas de género y orientada a cuestionar las normas de la sociedad patriarcal. Ese hibridismo nos empieza a plantear retos como el de la revisión de las categorías ya establecidas, por las implicaciones derivadas de términos como el del gótico y el de lo inusual. Bajo la expresión female gothic — acuñada por Ellen Moers en Literary Women: The Great Writers (1976) - se integran tanto obras realistas como de la estética de lo imposible. Más interesante es, sin embargo, centrar ahora la atención en la reciente etiqueta genérica de lo inusual, acuñada por Carmen Alemany Bay (2016) para designar la singularidad de voces femeninas en español que introducen elementos insólitos de sesgo metafórico en la representación de una realidad experimentada como hostil por personajes femeninos (Alemany Bay, 2019; García Valero, 2019). En el seno de esta narrativa de lo inusual sobresalen ficciones que inciden en las patologías de nuestras sociedades actuales y que denuncian sus incoherencias, con una enunciación singular que comulga con escritoras de varias generaciones en el rechazo de los estándares de representación femeninos propios del discurso conservador (Eudave, 2019: 43-58). 
Cecilia Eudave, maestra de una literatura de umbrales entre lo real y lo insólito, es una de las figuras representativas de esta narrativa de lo inusual. Opta por penetrar con agudeza en la existencia, en el malestar emocional tan extendido en la actualidad, así como en la atrocidad que el ser humano imprime al mundo. Y lo hace a través de múltiples registros y de una representación metafórica de la realidad, tanto de la interior como de la exterior, sin huir del lirismo, de lo mítico y del humor ${ }^{6}$.

Pero, para ser justos, conviene tener en cuenta que las autoras de lo insólito abordan, de entrada, los mismos motivos de la literatura no realista que los escritores: la problemática de la identidad, las especulaciones espaciotemporales, la metaficción, lo onírico, el doble, las metamorfosis, lo monstruoso, entre otros. En esta línea, se puede poner como ejemplo la antología Insólitas. Narradoras de lo fantástico en Latinoamérica y España (López-Pellisa y Ruiz Garzón, 2019), que ha constituido un fenómeno de visibilización importante de las creadoras hispánicas de literatura no mimética. En dicho volumen se recogen cuentos escritos por una treintena de mujeres de Latinoamérica y de España, de al menos dos tercios de los países hispanohablantes y de diferentes generaciones:

Entre los temas que se abordan entre estas páginas, a título de anticipo (dado que cada relato irá presentado con una biografía de la autora y una breve introducción al cuento), destacamos en cualquier caso la violencia de género, la relación con el Otro, la diversidad sexual, la soledad, la misoginia, los cuerpos no normativos, la infancia, la muerte, la enfermedad, las relaciones familiares, la metaliteratura, la licantropía, la precariedad laboral, el canon de belleza occidental, la violencia, la desigualdad de clases, el monstruo, la ecología, la guerra, el amor, la política en la era de la globalización, la relación humanomáquina, la educación en la era de la cibercultura, la inmigración o la indiferencia de la sociedad frente los problemas ajenos, entre otras posibilidades que invitamos a descubrir como quien destapa el ánfora de Pandora (López-Pellisa y Ruiz Garzón, 2019: XXX).

Esta antología pone de relieve la riqueza temática de lo insólito, cierto que no exclusiva de las autoras, pero también descubre que, junto a cuentos carentes de sesgo feminista, existen otros muchos en los que sí destaca una vertiente creadora en la que late una perspectiva política y reivindicativa.

Triunfa, pues, en el panorama literario actual y en un alto porcentaje, una prosa que no podemos dejar de definir como visceral y perturbadora. Una prosa que retrata nuestro mundo y nuestra identidad, pero que, de manera llamativa, se detiene en la mujer, en las atmósferas opresivas que esta padece, en sus frustraciones y en la violencia de género. Cada vez son más las escritoras que sorprenden con atmósferas opresivas que la mujer sufre o contra las que se rebela e, incluso, ante las que reacciona de forma agresiva. Es muy posible que ese tratamiento literario surja como consecuencia de la evolución propia

\footnotetext{
${ }^{6}$ Buena muestra de lo afirmado, entre otros muchos posibles ejemplos, la constituyen su novela breve Bestiaria vida (Eolas, 2018) o sus Microcolapsos (Eolas, 2019), entre ellos “Sábanas blancas”, que enfatiza las guerras, o "Pistolas", que dibuja la fragilidad humana en sociedades sórdidas, junto a otra línea que nos acerca al uso feminista de lo insólito. Pongamos como ejemplos de esta última vertiente "Recuerdos de una taza" y "El demonio de los viernes", que refleja la persistencia del maltrato machista contra la mujer.
} 
de los roles de género, como respuesta a la situación actual de la mujer, que sigue padeciendo grados de alienación y violencia que la ubican en un laberinto sin salida. Todo ello, y la posibilidad que tienen las escritoras de determinados ámbitos geográficos de alzar la voz, incrementa esta prosa descarnada, alejada de sentimentalismos. En ella se retrata la crueldad, tal como lo hacen muchos discursos masculinos, pero se analiza la realidad desde una perspectiva que diverge de la patriarcal a la hora de abordar temas como el amor, la familia o la maternidad. La narrativa de la argentina Valeria Correa Fiz nos permite ilustrar este hecho. Bajo el título La condición animal (Páginas de Espuma, 2016) - con poéticas de la incertidumbre, de terror, góticas, fantásticas y distópicas-, esta autora se interroga por aquello que nos define frente al resto de especies. Crueldad, brutalidad, sordidez y destrucción asoman en contextos históricos - testimonio del horror, injusticias sociales y políticas propias de un mundo de corrupción, de miseria y pobreza - y en ámbitos familiares — pareja, maternidad, paternidad, infancia enfrentada a la vida - Es tan solo un ejemplo, junto al de nombres tan destacados en el panorama literario de los últimos años como los de Samanta Schweblin y Mariana Enríquez, entre otros, que han acaparado una atención creciente de crítica, editoriales y público lector.

Lo mencionado hasta el momento nos hace interrogarnos sobre cómo se enuncian las mujeres desde un discurso propio, no heredero del patriarcal, lo que obliga a conceder atención a cómo trabajan, con algunos rasgos específicos, la mirada narrativa y las atmósferas insólitas a la hora de abordar la memoria, la familia, la infancia, la muerte, la otredad y el monstruo, en muchos casos a través del hibridismo genérico y de múltiples registros entre los que no renuncian al humor, a la parodia, al sarcasmo y a lo grotesco.

Por otro lado, existen obras muy interesantes que no despliegan explícitamente un enfoque feminista de lo no mimético. Por poner dos ejemplos de generaciones distintas en el ámbito español, podemos pensar en ficciones de la consagrada Cristina Fernández Cubas - Todos los cuentos (2008, Tusquets); La habitación de Nona (2015, Tusquets) o de Ana Martínez Castillo —Reliquias (Eolas, 2019)—, que se ha incorporado recientemente al corpus de lo insólito en nuestras letras. Cristina Fernández Cubas se inclina hacia lo fantástico, en general, aunque tiene obras que no cumplen con las reglas de esta categoría y se acercan a otras vertientes, como la de lo grotesco, lo insólito y el terror natural. En el caso de Ana Martínez Castillo incide en sus cuentos en los miedos que acompañan desde siempre al ser humano, y lo hace con relatos que exploran todas las categorías no miméticas: lo fantástico, el terror sobrenatural y lo distópico. Ambas autoras remiten con sus cuentos, igual que los escritores, al gran tema de la identidad, a otras preocupaciones del ser humano y a críticas a nuestras sociedades actuales. En principio, no parece haber diferencia, por lo tanto, entre lo insólito creado por hombre y mujer, algo lógico si rechazamos el esencialismo. No obstante, habría que hacer una puntualización, pues en ambas destaca el protagonismo femenino como agente, la existencia de voces narradoras de mujer, junto a matices en los motivos de sus cuentos que no se localizan con facilidad en los de firma masculina, por lo que sí podrían 
abordarse parcialmente desde un posible uso feminista de lo fantástico a pesar de que no sea esta su pretensión directa.

\section{EL DISCURSO SUBVERSIVO DE PATRICIA ESTEBAN ERLÉS}

La evolución de la literatura de lo insólito en las últimas décadas justifica la necesidad de desarrollar investigaciones sobre diversos aspectos de la poética fantástica vinculados a la vertiente de contestación al ideario conservador asumido por nuestro imaginario en relación con la construcción de la identidad de la mujer. En ellas, tal como se demostrará a continuación, no se pueden soslayar cuestiones como la selección y el tratamiento de los personajes, la temática, el hibridismo genérico, la construcción y la significación del espacio doméstico y del espacio del cuerpo, así como la monstruosidad derivada de la realidad sexista. Para demostrarlo, tomo en esta ocasión como punto de referencia a Patricia Esteban Erlés (Zaragoza, 1972), escritora española destacada en lo fantástico literario actual, en cuya narrativa sobresalen el protagonismo de la mujer y los conflictos de género que a esta afectan.

\section{1. ¿Hacia un canon reformulado?}

Esteban Erlés se reconoce dentro de una tradición de escritoras que apuesta por lo insólito, lo inquietante, lo extraño y lo fantástico. El canon que le influye se ha ido constituyendo con las voces masculinas destacadas de la literatura —en su caso, Poe, Nabokov, Capote, Cortázar y Arreola (en Muñoz, 2011: 390), entre otros-, pero también con muchas voces femeninas que no siempre han sido tenidas en cuenta. Es consciente de la invisibilización endémica de las escritoras y tiene palabras de reconocimiento y de apoyo hacia ellas, defendiendo que ya es hora de que estas se valoren por su calidad artística. Asimismo, constata las patologías de nuestra sociedad actual, de los seres otros, del considerado como diferente, del marginado, del que sufre cualquier tipo de violencia o abuso, o del que experimenta el dolor al que a veces la vida nos lleva. De ahí que utilice lo fantástico y lo insólito no para huir de la realidad sino para ofrecernos una visión crítica de la misma. Demuestra que se puede contar de una manera original, con la que logra poner de manifiesto todas las grietas y fisuras que resquebrajan constantemente nuestra supuesta normalidad cotidiana. Con esas premisas, Esteban Erlés ha creado un sólido universo literario, al que hay que añadir la publicación Fondo de armario (2019), en la que compendia sus artículos periodísticos. Resalto este título porque me parece que su contenido resume muy bien lo que el resto de su obra nos ofrece, que no es el escapismo que se asocia equívocamente a lo fantástico, sino una mirada comprometida con la realidad. A partir de una variada gama de temas, esta escritora construye en sus artículos 
una voz desde el "saber situado"7 de la intelectual comprometida, que ofrece testimonios de reivindicación social ${ }^{8} \mathrm{y}$ de género.

Centrando la atención en su ficción, hay que detenerse en los nombres que se pueden considerar como sus "madres fantásticas", tal como la propia autora ha reconocido. Entre ellas destacan Daphne du Maurier, Shirley Jackson y Patricia Highsmith. No en vano, la novela Rebecca, de du Maurier, y la versión cinematográfica dirigida por Alfred Hitchcock, le impactaron hasta el punto de revelarle la impronta del espacio doméstico en la vida de la mujer. Del mismo modo, le atrae el empleo de esa dimensión espacial en las narraciones de Shirley Jackson, autora que realza figuras narrativas femeninas e infantiles, y que no huye del humor, de la perversidad y del retrato de la monstruosidad que acecha en el entorno familiar y cotidiano. En un análisis comparativo entre ambas escritoras, Ana Calvo identifica en sus obras la irrupción de lo extraño, lo inesperado y lo incomprensible:

Nada es lo que parece y bajo la dicotomía mundo infantil-mundo adulto se introducen subrepticiamente lo siniestro y lo macabro en escenarios domésticos. Conscientes de que la cotidianidad tiene lados oscuros y ángulos inquietantes y de que las mujeres de todos los tiempos han necesitado encarnar sus miedos a través de la creación de criaturas monstruosas y temibles, ambas construyen un imaginario doméstico siniestro (Calvo, 2020b: 177).

Otra de sus creadoras favoritas es Patricia Highsmith, con la que comparte la fascinación por el mal, la perversión y el peligro de la bestialidad que se esconde en el lado más oscuro del ser humano ${ }^{9}$. Los referentes internacionales irán incrementándose, incluyendo figuras como las de Angela Carter y las de las maestras anglosajonas del relato sobrenatural, gótico, terrorífico o maravilloso de finales del siglo XIX y principios del XX.

En el ámbito hispano contempla a maestras de otras generaciones. En relación con el corpus español, ensalza la figura de Emilia Pardo Bazán, a la que admira por razones estéticas y por su visión crítica de la realidad del momento, en la que se incluye la percepción de la violencia de género como un mal social. Además, declara sentirse fascinada por el universo literario de Ana María Matute, a la que remite cuando se le pregunta por el tema del monstruo: "Me gusta mucho la monstruosidad infantil, el monstruo en la infancia, el niño extraño, como los niños de Ana María Matute, por ejemplo. Una manera de abordar la monstruosidad muy interesante. La maldad infantil,

\footnotetext{
${ }^{7}$ Expresión de Donna Haraway (1995).

${ }^{8}$ También en sus microrrelatos hipermediales se perciben esos contenidos sociales y éticos. Para obtener más información al respecto, recomiendo el estudio de Ana Calvo (2020a).

9 “[...] porque realmente descubrir sus libros de cuentos Una afición peligrosa o Pájaros a punto de volar fue conocer el filo inquietante que siempre tiene la vida cotidiana, la amenaza que se oculta detrás de los seres más inofensivos. En su literatura una inocente alfombra comprada en un mercadillo puede convertirse en cómplice de un crimen, en el motor de un asesinato, y ella, con toda la mala leche del mundo te va suministrando los datos, la construcción de esa idea, el mecanismo mental que lleva a alguien a ayudarse de un objeto cotidiano para consumar el horror" (Esteban Erlés en Muñoz, 2011: 390).
} 
la crueldad" (Esteban Erlés en Álvarez Méndez, 2016: 62). Recordemos que las niñas de su novela Las madres negras son herederas de Los niños tontos (1956), de Ana María Matute: niñas tontas, indefensas, inocentes, necesitadas de amor, con deformidades físicas o enfermedades, que se enfrentan a la marginación, a la crueldad y a la muerte, que ven ultrajadas sus infancias y no encuentran su sitio ni en el mundo adulto ni en el infantil, por lo que solo pueden tratar de huir de estos a través de la fantasía, de la imaginación y de la muerte.

Confiesa, asimismo, su admiración por una de las maestras del cuento fantástico español, Cristina Fernández Cubas. Cuando se les pregunta a ambas por sus referentes literarios no miméticos incluyen nombres como los de Mary Shelley y la mencionada Emilia Pardo Bazán — siendo la primera una referencia indiscutible para los autores masculinos que, sin embargo, no citan con la misma frecuencia a la segunda- Fernández Cubas y Esteban Erlés sienten atracción por los espacios interiores con carga emocional y por la creación de atmósferas inquietantes, abordan la alienación y la angustia ante la decepcionante realidad cotidiana y familiar, y se rinden ante la fascinación por la infancia en sus ejes de ternura/crueldad y por la mirada infantil no contaminada y poseedora de un especial código de valores, sean estos últimos inocentes o malévolos. Podría parecer que estos aspectos citados son comunes también a la autoría masculina, pero hay una diferencia que radica en la perspectiva con la que se construyen literariamente esos ejes narrativos, vinculada a personajes femeninos agentes que ostentan el protagonismo en muchas de sus tramas. Otro aspecto interesante en Cristina Fernández Cubas es la introducción del cuento infantil en su ficción. Por ejemplo, en La habitación de Nona (2015), en cuyas narraciones aparecen personajes e intrigas que se pueden identificar con Caperucita Roja o Hansel y Gretel. Este recurso le permite hacer una crítica de paradigmas de comportamientos humanos, ahondando en la maldad y en la crueldad actual, tal como ha hecho Esteban Erlés en su novela Las madres negras.

Finalmente, no podemos pasar por alto que el peso de Silvina Ocampo en la tradición de la literatura no mimética es indiscutible. Esteban Erlés, que ha declarado que esta maestra de la crueldad es su autora preferida ${ }^{10}$, coincide con ella en el interés por la transgresión de los estereotipos femeninos y en la visión siniestra de la niñez. Ambas cultivan las posibilidades fantasmáticas y plásticas del lenguaje, así como la funcionalidad narrativa del detalle, al que cargan de significados profundos, y configuran un retrato de la crueldad, de lo siniestro, de la extrañeza, y de la belleza del horror, en el que no está exento el sentido del humor.

\footnotetext{
10 "Mi autora favorita desde siempre es Silvina Ocampo. Creo que es una maestra de la crueldad y que sus cuentos conforman un universo femenino inquietante, lleno de vestidos envenenados, de broches en forma de insecto, de alcobas donde suceden cosas terribles, de cerraduras, de animales disecados. La infancia es en sus relatos casi un periodo de supervivencia, de superación de experiencias espantosas. Sus historias están cargadas de misterio, escritas desde un humor casi doloroso, tienen una fuerte carga visual, casi pictórica y esconden ecos de tradición literaria clásica que ella fue capaz de reasumir y volcar convertida en otra cosa" (Esteban Erlés en Muñoz, 2011: 390).
} 
Existen, por lo tanto, conexiones y concomitancias de fondo entre lo que cuentan estas autoras y cómo lo narran. Muchas realizan una lectura crítica de la situación experimentada por la mujer, atendiendo en cada caso a las circunstancias concretas y a las individualidades que constituyen la identidad femenina, junto a los condicionantes de época y de ámbito geográfico, directamente vinculados ambos a las formas de dominación que afectan a dicha identidad.

\subsection{El discurso subversivo de Patricia Esteban Erlés en el contexto de lo fantástico feminista}

Podemos concretar dos vertientes que confluyen en la delimitación de una poética específica asociada a la mujer, poética no extrapolable a todas las creadoras pero sí destacada en un elevado porcentaje: 1) la selección de personajes femeninos y su caracterización y 2) temas asociados tradicionalmente a lo considerado como femenino - la alienación de la mujer, la problemática de la maternidad, el amor, la familia, etc.pero visitados desde una dimensión ideológica en el contexto de un marcado hibridismo.

En cuanto a la selección y el tratamiento de los personajes es significativa la importancia de las voces narrativas femeninas que cobran protagonismo en las ficciones de estas escritoras, así como las etapas de la infancia y adolescencia entroncadas con visiones siniestras de la niñez y de la etapa de madurez de la mujer en la que esta se enfrenta a realidades decepcionantes y a la denuncia de los modelos culturales femeninos impuestos. Esto sucede en la prosa de Esteban Erlés:

The recurrent employment of female narrative voices is a guideline to the motifs bearing witness to the traditional subordination of women perpetuated by conventional models of femininity. These include the ideals of beauty and perfection associated with the body; the role of angel in the house; the romantic ideal and patriarchal concept of the couple; the imaginary world created by popular culture, fairy tales, cinema and comic, fashion and advertising, traditional toys, and so forth. These transmit a discourse whose ideological content is supported by conservative values (Álvarez Méndez, 2019: 639).

En cuanto a la segunda vertiente, la dimensión ideológica de lo fantástico ha sido reseñada por la crítica (Jackson, 1981; Gregori, 2015; Campra, 2019) y no cabe duda de sus vínculos con la potencialidad de subversión en la creación de las escritoras. De ahí que no deba extrañar que lo ideológico impregne inevitablemente muchos de los recursos estructurales y temáticos del fantástico feminista, tal como se remarcará a continuación.

Conviene tener en cuenta que el hibridismo genérico - que no es un rasgo exclusivo de las escritoras, pues caracteriza la narrativa fantástica posmoderna en España (Roas, Álvarez y García, 2017: 210-211)—, se convierte en un recurso enriquecido en el caso de la autoría de mujer. Entre las lecturas que la propia Esteban Erlés reivindica se hallan muchas obras con firma femenina que tienen interesantes conexiones con el horror, el terror, lo descarnado y lo perturbador. En su propia narrativa, al horror que tiene su origen en el ámbito que habitan sus personajes, se une el terror que surge de lo más profundo de 
estos, vinculando lo fantástico con el gótico sobrenatural y con lo macabro ${ }^{11}$. Tal como constata Ana Abello Verano, sobresale en Esteban Erlés la combinación de su ficción fantástica con "diversos motivos de raíz gótica, ya sean narrativos o cinematográficos", lo que le lleva a analizar "el papel que esos rasgos góticos de tipo sobrenatural juegan en el desarrollo de las tramas y cómo la autora los emplea para dejar abierto el abismo de la incertidumbre" (2019: 31) ${ }^{12}$. En esa línea, muchos de los seres de su ficción se entrelazan con lo monstruoso, reflejo de la parte más oscura, tormentosa, irracional y secreta del propio ser humano. En las obras de las autoras citadas se conjuga lo fantástico con lo macabro en su revisión de los esquemas realistas y patriarcales de nuestro presente. Cobra fuerza la vertiente de personajes góticos acechados por la locura, así como por espacios domésticos ominosos que, hibridados con lo fantástico, ponen de relieve la lectura crítica de la situación experimentada por la mujer.

Con ellas comparte el interés por dichos espacios, por el protagonismo femenino, los procesos de alienación, la difícil situación de la mujer y el humor perverso. Y, aunque ni el hibridismo de estéticas no miméticas ni el de lo fantástico con el humor son recursos exclusivos de las escritoras, sí podemos rastrear su uso en las ficciones de gran parte de sus "madres fantásticas", orientadas, igual que en su obra, a la deconstrucción de las concepciones tradicionales impuestas, como hace, por ejemplo, Silvina Ocampo. Coinciden ambas en el cultivo de lo grotesco, categoría que combina lo humorístico y lo terrible, incluyendo este último "lo monstruoso, lo terrorífico, lo macabro, lo escatológico, lo repugnante o lo abyecto" (Roas, 2009: 15). Esteban Erlés no duda en entrelazar el humor con el horror fantástico con el fin de contar el miedo de una manera crítica (Esteban Erlés en Álvarez Méndez, 2016: 66) ${ }^{13}$. Lo demuestra, a su vez, el análisis de la ironía feminista en su obra realizado por Anna Boccuti (2020). Y las declaraciones de la autora lo confirman:

Me gusta plantear desde el humor negro o lo grotesco según qué realidades, como por ejemplo las relaciones de pareja o el hecho mismo de ser mujer. En algunos casos creo que empleo la provocación como llamada de atención sobre algo. Rizando el rizo, exagerando, caricaturizando, se puede criticar con mucha más libertad y claridad. El mensaje es más directo que hacer que los personajes, por ejemplo, mantengan una sesuda discusión sobre algo. La hipérbole, la ironía, son instrumento que ganan por K.O. a la digresión, sobre todo en una distancia breve como la del cuento o microcuento (Esteban Erlés en Jiménez Tapia, 2018: 214).

Otro punto de conexión es la atracción por los cuentos populares. En su novela Las madres negras entronca lo fantástico con el gótico y el cuento infantil, además de con la

\footnotetext{
11 El hibridismo no solo es genérico en el caso de Esteban Erlés, pues lo combina con el hibridismo semiótico en sus microrrelatos hipermediales (Calvo Revilla, 2020c).

12 Junto a los de otros autores, los ecos góticos en los microrrelatos de Esteban Erlés han sido analizados por Rosa María Díez Cobo (2019). Asimismo, en su utilización de lo siniestro y del terror ha profundizado Ana Calvo Revilla (2019).

${ }^{13}$ Solo se observa la ausencia de ese humor en su novela Las madres negras.
} 
mitología y el realismo mágico. Todas esas estéticas se delimitan con una envoltura poética que nos ofrece la visión de un mundo mágico y perturbador a partes iguales, marcado por la lucha eterna entre el bien y el mal bajo el peso del fanatismo y del patriarcado. De ahí que en esta narración se proyecte una inversión de los modelos tradicionales reproducidos en los cuentos de hadas ${ }^{14}$ : la libertad y la sabiduría proceden de las brujas y del lobo, mientras que lo tenebroso y la monstruosidad se vinculan a las instancias religiosas que deberían ofrecer protección. En el microrrelato "Princesas rana" (Casa de Muñecas) se propone un juego literario que testimonia el contenido ideológico conservador de los cuentos populares:

Las princesas rana eran pequeñas y verdes. No las dejaban salir de palacio, pero ellas solían escaparse los días de lluvia y saltaban por los jardines envueltas en sus diminutos trajes de novia. El rey nos ordenaba que las capturásemos sin demora y salíamos en su busca, muertos de asco. Pero bastaba con mirarlas un instante para comprender aquella desesperación resbaladiza que asomaba a sus ojos, cuando nos arrodillábamos a su lado y dejaban que las atrapáramos. Pedían a gritos un beso. Nosotros tan solo las devolvíamos al interior del estanque (Esteban Erlés, 2012: 125).

Los personajes femeninos se convierten en agentes de la acción narrativa y ponen de manifiesto el daño ocasionado por una educación represiva y por la ausencia de afectividad en el ámbito familiar, recreando tramas con abuelas perversas, madres represoras y hermanas poco fraternales que rompen con el papel tradicional asociado a esas figuras. Los ejemplos se multiplican en su obra, sirva como ejemplo el microrrelato "La gemela fea" (Casa de Muñecas):

Te peinaré siempre que tú me lo pidas, le decía la gemela fea a la gemela guapa, asumiendo su papel de pequeña doncella condenada a las sombras. A la gemela guapa le gustaba escuchar cerca la respiración perruna de su hermana, saberla despierta en la oscuridad las noches de tormenta en que velaba su sueño. Te prohíbo dormir, le decía, no te duermas antes que yo, y si viene el monstruo, tiene que comerte a ti primero y me avisas mientras te esté devorando para que me dé tiempo a escapar. La gemela fea agitaba la cabeza. Obedecía y aguantaba la respiración, le anudaba el lazo del vestido, lustraba sus zapatos blancos de charol, cualquier cosa que ella le pidiera era una orden, el deseo irrevocable de un ser perfecto, de esa versión idealizada de sí misma, la que estuvo a punto de ser y no fue. La gemela fea continuó peinándola cada noche, alisando cada mechón de su cabello una y cien veces ante el espejo, aunque la gemela guapa llorara bajito y le dijera que ya no, que por favor ya no. Sorda, como la lealtad de un perro que no deja de amarte ni muerto (2012: 46).

Como se percibe, además, en el anterior ejemplo, esas complejas relaciones genealógicas se recrudecen en muchas ocasiones por la competitividad entre mujeres por causa de la belleza y los celos. Este motivo vuelve a plantearse en Las madres negras,

${ }^{14}$ Hecho sobre el que se profundiza en Raquel de la Varga Llamazares (2019). 
novela en la que, sin embargo, aparece por primera vez en la obra de la zaragozana el desarrollo de la sororidad.

En "Domestic Horror and Gender Conflicts in the Narrative of Patricia Esteban Erlés" (Álvarez Méndez, 2019) se ha detallado el empleo que hace la autora del espacio doméstico asociado al horror en la construcción de historias que realzan las vidas y las voces de mujeres asediadas por el peso de la tradición heteropatriarcal. Con el fin de profundizar en dicho objeto de estudio, ese artículo analiza sus libros de cuentos Manderley en venta (2008a), Abierto para fantoches (2008b) y Azul ruso (2010), y su volumen de microrrelatos Casa de Muñecas (2012). Y atiende a cómo se refleja dicho horror doméstico en los paratextos y en las ilustraciones que acompañan a algunos de sus libros. Su objetivo es demostrar que las representaciones de lo femenino que recorren su narrativa desvelan - a través de la fragilidad de las relaciones humanas, tanto familiares como de pareja, y mediante ámbitos hogareños monstruosos imbuidos de crueldad - la perpetuación de los modelos de mujer implantados en nuestras sociedades. En ese sentido, no hay que olvidar que el espacio narrativo se convierte en el marco de lo no mimético en uno de los posibles elementos de la transgresión fantástica (García, 2015; Eudave, 2018). En el caso de Esteban Erlés, la casa —incluidas las encantadas ${ }^{15}$ — evidencia cómo el espacio familiar y cotidiano es el que atenaza de modo constante y descarnado a los personajes femeninos. Con el tratamiento literario de esa entidad narrativa se consigue testimoniar las imposiciones patriarcales que han sometido a la mujer. Pensemos en el último microrrelato de Casa de Muñecas, "Luz encendida", muy simbólico en su propuesta de un intercambio de identidades entre la casa y la figura femenina que por tradición ha padecido en ese marco físico el peso de la opresión patriarcal:

La vi mirarme a lo lejos, comprendí que algo raro había pasado. Ella llevaba puesto mi vestido rojo, yo su tejado. Echó a correr como una loca, feliz de ser tan liviana. No pude seguirla. Sus cimientos de doscientos años y el peso de sus vigas de roble me lo impidieron. Por el camino la vi descalzarse, la vi soltarse el pelo, decirme adiós agitando la mano. Aquella noche ya no regresó y eso que estuve esperando hasta el alba, con la luz del porche encendida... (2012: 177).

A su vez, la representación del espacio del cuerpo contribuye a la denuncia de género en la obra de narradoras de lo insólito en español (Eudave, 2019). Este eje temático posibilita en Esteban Erlés la crítica a las concepciones tradicionales de familia y de pareja, así como a los cánones de belleza impuestos a la mujer. Los ejemplos se suceden en su narrativa. Por ejemplo, el intercambio de identidades corporales que se produce en "Línea 40" (Manderley en venta), que asocia la corporalidad femenina a un objeto sexual, aborda la problemática de la explotación de la mujer por parte de los hombres y delata el

\footnotetext{
${ }^{15}$ Entre las que no se puede dejar de citar Santa Vela, el convento de Las madres negras, que tiene el mismo protagonismo que el resto de personajes, pues no se reduce a un espacio gótico clásico sino que adquiere vida propia a través de la personificación y se convierte en uno de los ejes catalizadores del mal. Otros cuentos significativos, como "Habitante" (Manderley en venta), han sido analizados en profundidad en relación con el motivo de la casa encantada (Díez Cobo, 2020).
} 
peso de la cirugía estética en la sociedad actual. Otros textos profundizan, con diversos matices, en el enfermizo culto al cuerpo que se convierte en otra forma de opresión. Y algunas ficciones insisten en estos motivos a través de la simbología de las muñecas — siniestras dobles del ser humano- vinculadas a lo oscuro y lo terrorífico ${ }^{16}$.

En relación con el monstruo, cuya relevancia ya se ha ido sugiriendo en los ejemplos citados hasta el momento, son de interés las siguientes afirmaciones de la autora:

Yo sin monstruos no querría vivir. Directamente, ni querría escribir. A mí me parece que es el personaje más interesante de todos los que uno puede abordar. Porque no pensemos en un monstruo tipificado, el monstruo lo bueno que tiene es que puede ser mil. Un monstruo puede tener mil caras diferentes y dar todas mucho miedo, algunas veces te dan compasión. A mí me gusta del monstruo, sobre todo, la faceta de criatura marginal: el monstruo siempre es el otro. Y me gusta mucho el cambio de percepción que hay cuando cambia una sociedad cómo también cambia su visión del monstruo. Cómo el monstruo de la Edad Media no es el monstruo del siglo XIX ni es el monstruo contemporáneo; me gusta mucho esa versatilidad que tiene. Y me gusta mucho que del monstruo casi nunca sabemos nada. El monstruo es una especie de recipiente sobre el que todo el mundo puede opinar, al que todo el mundo puede temer, despreciar, pero pocas veces tenemos la visión del monstruo y eso me parece muy interesante. Es una criatura hermética y la vamos construyendo los demás, los aparentemente normales, o los que no cabríamos dentro de esa tipificación de monstruo (Esteban Erlés en Álvarez Méndez, 2016: 62).

Consciente de que el monstruo es una metáfora de nuestros miedos y una proyección de lo humano, introduce en sus cuentos y microrrelatos seres monstruosos variados que traslucen pulsiones reprimidas y temores colectivos. Pensemos en los numerosos fantasmas, espíritus que no renuncian a permanecer en los que fueron sus hogares, desde los clásicos espectros a aquellos que ponen de relieve el fracaso de las relaciones amorosas, pasando por variantes en las que se rodean de una mirada humorística - "El hombre que amé se ha convertido en fantasma. Me gusta ponerle mucho suavizante, plancharlo al vapor y usarlo como sábana bajera las noches que tengo una cita prometedora" ("Fantasma. Homenaje a J. J. Arreola", Casa de muñecas, 2012: 117) — o de una envoltura melancólica, como sucede en "Cantalobos" (Manderley en venta), en el que los fantasmas no reconocen su estado. De igual modo, sobresalen aquellos que se convierten en narradores, enmarcados en lo que la crítica ha denominado como "la voz del Otro" (Campra, 1991: 59), recurso asentado en los rasgos del fantástico español posmoderno (Roas, Álvarez y García, 2017: 206-208).

Hacia lo monstruoso nos conducen las metamorfosis asociadas a la animalización, que nos arrastran "al remoto mundo de la bestialidad y de las transformaciones de los cuerpos y de las naturalezas" (Ceserani, 1999: 123), en el marco de uno de los ejes temáticos recurrentes en la literatura fantástica que nos enfrenta a lo no cognoscible. Pensemos en "Azul ruso" (Azul ruso) o en "Isobel” (Casa de muñecas). El vínculo de lo femenino y lo perverso, la locura, lo diabólico y la brujería se potencia en muchas de sus

${ }^{16}$ Ejemplos de las figuraciones fantásticas de las muñecas en sus microrrelatos en Álvarez Méndez (2019). 
ficciones. La propia Emma Zunz, protagonista del citado cuento "Azul ruso" se identifica con Circe (Velázquez Velázquez, 2019: 603) y se describe como una figura terrorífica que condena a los hombres y que, "en su baño semanal, como en el mito de Melusina, se transforma en una gata blanca, fruto de su castigo" (Sánchez Aparicio, 2013: 217).

En muchas de sus narraciones las protagonistas abandonan la sumisión para convertirse en mujeres fatales o en seres monstruosos ${ }^{17}$, amenazadoras para el hombre, pero también para otras mujeres. No en vano, perfilan el machismo estructural e ideológico implantado en la sociedad que aboca a la mujer a la competencia con otras, así como a la alienación o la contestación del modelo de mujer angelical en favor del de la mujer monstruosa:

Although this latter option might be considered a metaphoric attempt to protest against impositions due to their sex, the frequent allusions to women sexualized or rendered invisible is a denunciation of the acceptance of archetypes that should no longer be valid in the present age. Her narratives insist so strongly upon the need to create a more realistic image of women, free from conventional stereotypes, that will at last be diverse and complete (Álvarez Méndez, 2019: 639).

\section{CONCLUSIONES}

No cabe duda del auge de las creadoras hispánicas de lo insólito que - desde el marco de lo sugerido, lo metafórico, lo simbólico y la ambigüedad - configuran una literatura de umbrales entre lo fantástico y sus fronteras, con un alto porcentaje de obras que se encaminan a una interpretación feminista que cuestiona los valores tradicionales desde una perspectiva no abordada con la misma mirada y matices en las obras de firma masculina. Sus textos no pasan por alto una necesaria denuncia de la problemática femenina y de la violencia de género en todas sus vertientes.

Con la certera visión crítica desplegada por esas autoras confluye la ficción de Patricia Esteban Erlés. A la reflexión sobre la sociedad y la condición humana le suma una postura ética ante el feminismo. De tal forma, cuestiona el canon institucionalizado, reivindica la autoría de escritoras que han de ser tenidas en cuenta como puntos de referencia para las nuevas generaciones, expone la problemática derivada de la condición de ser mujer en un mundo construido desde la ideología patriarcal, y refleja los modelos de representación de lo femenino y los espacios claustrofóbicos que la mujer suele habitar y con los que establece una intensa relación metonímica o metafórica. Todo ello lo logra mediante el cultivo de las estéticas no miméticas — con especial énfasis en lo fantástico, pero recurriendo al gótico, lo mítico, lo maravilloso y el realismo mágico-, que le permiten traslucir la monstruosidad que se oculta en el lado más oscuro del ser humano, evidenciando modos y conductas culturales.

${ }^{17}$ Para completar información al respecto, véase Raquel de la Varga Llamazares (2015). 


\section{REFERENCIAS BIBLIOGRÁFICAS}

Abello Verano, A. (2016). "Narrativas de lo (in)cierto: consideraciones sobre lo fantástico en la cuentística española actual". En Territorios de la imaginación: poéticas ficcionales de lo insólito en España and México, N. Álvarez Méndez, A. Abello Verano y S. Fernández Martínez (eds.), 17-33. León: Servicio de Publicaciones de la Universidad de León.

(2019). “Cartografías de lo sobrenatural. Fantástico e imaginería de terror gótico en la narrativa breve de Patricia Esteban Erlés". Dicenda. Estudios de Lengua y Literatura Españolas 37, 31-49. Disponible en línea: https://revistas.ucm.es/index.php/DICE/article/view/64993/4564456551700 [10/12/2020].

Alemany BAy, C. (2016). "Narrar lo inusual: Bestiaria vida de Cecilia Eudave y El animal sobre la piedra de Daniela Tarazona". Romance Notes 56.1, 131-142. (2019). “Una nueva modalidad de lo insólito en tiempos posmodernos? La narrativa de lo inusual". En Realidades fracturadas. Estéticas de lo insólito en la narrativa en lengua española (1980-2018), N. Álvarez Méndez y A. Abello Verano (eds.), 307-324. Madrid: Visor Libros.

Álvarez MÉNDEZ, N. (2013). "Introducción: Lo fantástico en la cultura española del siglo XXI”. Brumal. Revista de Investigación sobre lo Fantástico I.2, 195-200. Disponible en línea: https://revistes.uab.cat/brumal/article/view/v1-n2-alvarezmendez/pdf-es [10/12/2020].

(2016). "Conversación con escritores de la imaginación: Patricia Esteban Erlés, Alberto Chimal y Juan Jacinto Muñoz Rengel”. En Territorios de la imaginación: poéticas ficcionales de lo insólito en España and México, N. Álvarez Méndez, A. Abello Verano y S. Fernández Martínez (eds.), 51-68. León: Servicio de Publicaciones de la Universidad de León.

(2019). "Domestic Horror and Gender Conflicts in the Narratives of Patricia Esteban Erlés". Bulletin of Hispanic Studies 96.6, 627-640.

Alpini, G. (2009): The Female Fantastic. Evolution, Theories and Poetics of Perversion. Fano: Aras Eidizioni.

BoccuTi, A. (2020). "Modulaciones de lo insólito, subversión fantástica e ironía feminista: ¿una cuestión de género(s)?”. Orillas 9, 151-176.

Butler, J. (2001). El género en disputa. El feminismo y la subversión de la identidad. México: Paidós.

Calvo Revilla, A. (2019). "Lo siniestro y la subversión de lo fantástico en Casa de muñecas, de Patricia Esteban Erlés". En Pasado, presente y futuro del microrrelato hispánico, M. Martínez Deyros y C. Morán (eds.), 113-132. Berlín: Peter Lang. 
(2020a). "Social Criticism and Ethical Aspects in Patricia Esteban Erlés and Abert Soloviev's Hypermedial Short Stories”. Cultura. International Journal of Philosophy of Culture and Axiology 17.2, 99-115.

(2020b). "El horror doméstico en la narrativa breve de Patricia Esteban Erlés y Shirley Jackson”. Iberoromania 92, 177-200.

(2020c). "Microrrelato hipermedial. Hibridismo semiótico en la obra de Patricia Esteban Erlés". Co-herencia. Revista de Humanidades 17.33, 101-131. Disponible en línea: https://publicaciones.eafit.edu.co/index.php/coherencia/article/view/5938/5039 [22/12/2020].

CAMPrA, R. (1991). "Los silencios del texto en la literatura fantástica". En El relato fantástico en España e Hispanoamérica, E. Morillas Ventura (ed.), 49-73. Madrid: Siruela. (2019). En los dobleces de la realidad. Exploraciones narrativas. León: Eolas.

CESERANI, R. (1999). Lo fantástico. Madrid: Visor Libros.

Cixous, H. (1995). La risa de la medusa. Ensayos sobre la escritura. Barcelona: Anthropos.

Cranny-Francis, A. (1990). "Feminist Fantasy". En Feminist Fiction: Feminist Uses of Generic Fiction. New York: St. Martin's Press.

DíEz CoBo, R. M. a (2019). "Ecos góticos en el microrrelato contemporáneo en español: una travesía en/tre orillas atlánticas”. Microtextualidades. Revista Internacional de microrrelato y minificción 5, 45-66. Disponible en línea: https://revistas.uspceu.com/index.php/microtextualidades/article/view/146/112 [10/12/2020].

(2020). "Arquitecturas del hogar invertido: reescribiendo la casa encantada". Brumal. Revista de Investigación sobre lo Fantástico VIII.1, 135-156. Disponible en línea: https://revistes.uab.cat/brumal/article/view/v8-n1-diez-cobo/pdf-es-40 [10/12/2020].

ESTEBAN ERLÉS, P. (2008a). Manderley en venta. Zaragoza: Tropo Editores. (2008b). Abierto para fantoches. Zaragoza: Diputación Provincial. (2010). Azul ruso. Madrid: Páginas de Espuma. (2012). Casa de Muñecas. Madrid: Páginas de Espuma. (2018). Las madres negras. Barcelona: Galaxia Gutenberg. (2019): Fondo de armario. Zaragoza. Contraseña.

EUDAVE, C. (2018). "Hacia una clasificación del espacio en textos de horror fantástico". Brumal. Revista de Investigación sobre lo Fantástico VI.2, 57-73. Disponible en línea: $\quad$ https://revistes.uab.cat/brumal/article/view/v6-n2-eudave/pdf_39_es [10/12/2020].

(2019). "El cuerpo como espacio de lo insólito en la narrativa mexicana reciente escrita por mujeres". En Realidades fracturadas. Estéticas de lo insólito en la narrativa en lengua española (1980-2018), N. Álvarez Méndez y A. Abello Verano (eds.), 43-58. Madrid: Visor Libros. 
Foucault, M. (1979). Microfísica del poder. Madrid: La Piqueta. (1994). Hermenéutica del sujeto. Madrid: La Piqueta.

García VAlero, B. (2019). "Para una teoría de lo inusual. Procedimientos lingüísticos, planteamientos estéticos". En Realidades fracturadas. Estéticas de lo insólito en la narrativa en lengua española (1980-2018), N. Álvarez Méndez y A. Abello Verano (eds.), 325-338. Madrid: Visor Libros.

GarcíA, P. (2015). Space and the Postmodern Fantastic in Contemporary Literature. The Architectural Void. New York / London: Routledge. (2019). "Introduction: Gender and the Hispanic Fantastic". Bulletin of Hispanic Studies 96.6, 569-573.

GREGORI, A. (2015). La dimensión política de lo irreal. El componente ideológico en la narrativa fantástica española y catalana. Poznan: WN UAM.

HARAWAY, D. (1995 [1991]). Ciencia, cyborgs y mujeres: la reinvención de la naturaleza. Madrid: Cátedra.

JACKSON, R. (1981). Fantasy, the literature of subversion. New York: New Accents.

JiMÉNEZ TAPIA, G. (2018). "Entrevista a Patricia Esteban Erlés". Microtextualidades. Revista Internacional de microrrelato y minificción 3, 212-216. Disponible en línea:https://revistas.uspceu.com/index.php/microtextualidades/article/view/116/ $72[10 / 12 / 2020]$.

LÓPez-Pellisa, T. y Ruiz Garzón, R., EDS. (2019). Insólitas. Narradoras de lo fantástico en Latinoamérica y España. Madrid: Páginas de Espuma.

MoErs, E. (1976). "Female Gothic". En Literary Women: The Great Writers, 90-98. Nueva York: Doubleday.

MuÑoz, M. A. (2011). La familia del aire. Entrevistas con cuentistas españoles. Madrid: Páginas de Espuma.

RICHTER, A. (1977). Le fantastique féminin d'Ann Radcliffe à nos jours. Verviers: Marabout.

RoAs, D. (2009). "Poe y lo grotesco moderno". $452^{\circ}$ F. Revista de Teoría de la Literatura y Literatura Comparada, 1, 13-27.

(2011). Tras los límites de lo real. Una definición de lo fantástico. Madrid: Páginas de Espuma.

(2020). "Fantástico femenino vs. Fantástico feminista. Género y transgresión de lo real”. En Las creadoras ante lo fantástico. Visiones desde la narrativa, el cine y el cómic, D. Roas y A. Massoni (eds.), 15-29. Madrid: Visor Libros.

RoAs, D.; Álvarez, N. y GarcíA, P. (2017). "Narrativa 1980-2015”. En Historia de lo fantástico en la cultura española contemporánea (1900-2015), D. Roas (dir.), 195-214. Madrid / Frankfurt: Iberoamericana / Vervuert.

ROAS, D. Y CASAS, A., EDS. (2008). La realidad oculta. Cuentos fantásticos españoles del siglo XX. Palencia: Menoscuarto. (coords.) (2010). “Lo fantástico en España (1980-2010)”. Monográfico de Ínsula. Revista de Letras y Ciencias Humanas 765, 2-34. 
SÁNCHEZ APARICIO, V. (2013). "Horrores generacionales: visiones de la derrota en los relatos de Patricia Esteban Erlés y David Roas”. Brumal. Revista de Investigación sobre lo Fantástico, I.2, 201-221. Disponible en línea: https://revistes.uab.cat/brumal/article/view/v1-n2-sanchez-aparicio/pdf-es [10/12/2020].

VARga Llamazares, R. DE la (2015). "Mujeres que matan. Dimensiones del monstruo en la narrativa de Patricia Esteban Erlés". En Espejismos de la realidad: percepciones de lo insólito en la literatura española (siglos XIX-XXI), N. Álvarez Méndez y A. Abello Verano (eds.), 233-242. León: Servicio de Publicaciones de la Universidad de León.

(2019). "Figuraciones de la femme fatale en Las madres negras de Patricia Esteban Erlés". En Realidades fracturadas. Estéticas de lo insólito en la narrativa en lengua española (1980-2018), N. Álvarez Méndez y A. Abello Verano (eds.), 287-303. Madrid: Visor Libros.

VELÁZQUEZ, R. (2019): “Quaerens quem devoret: El resurgimiento de la mujer mantis o mujer devoradora en el microrrelato fantástico español del siglo XXI". Bulletin of Hispanic Studies 96.6, 595-610.

Fecha de recepción: 10/12/2020

Fecha de aceptación: 05/03/2021 